\title{
Ecologia e Juízo Moral: Vozes de Líderes Ambientais em Rondônia
}

\author{
Ecology and Moral Judgement: \\ Voices of Environmental Leaders in \\ The Brazilian State of Rondônia \\ Ecología y Juicio Moral: \\ Voces de Líderes Ambientales en Rondônia
}

Vanessa Aparecida Alves de Lima

Universidade Federal de Rondônia
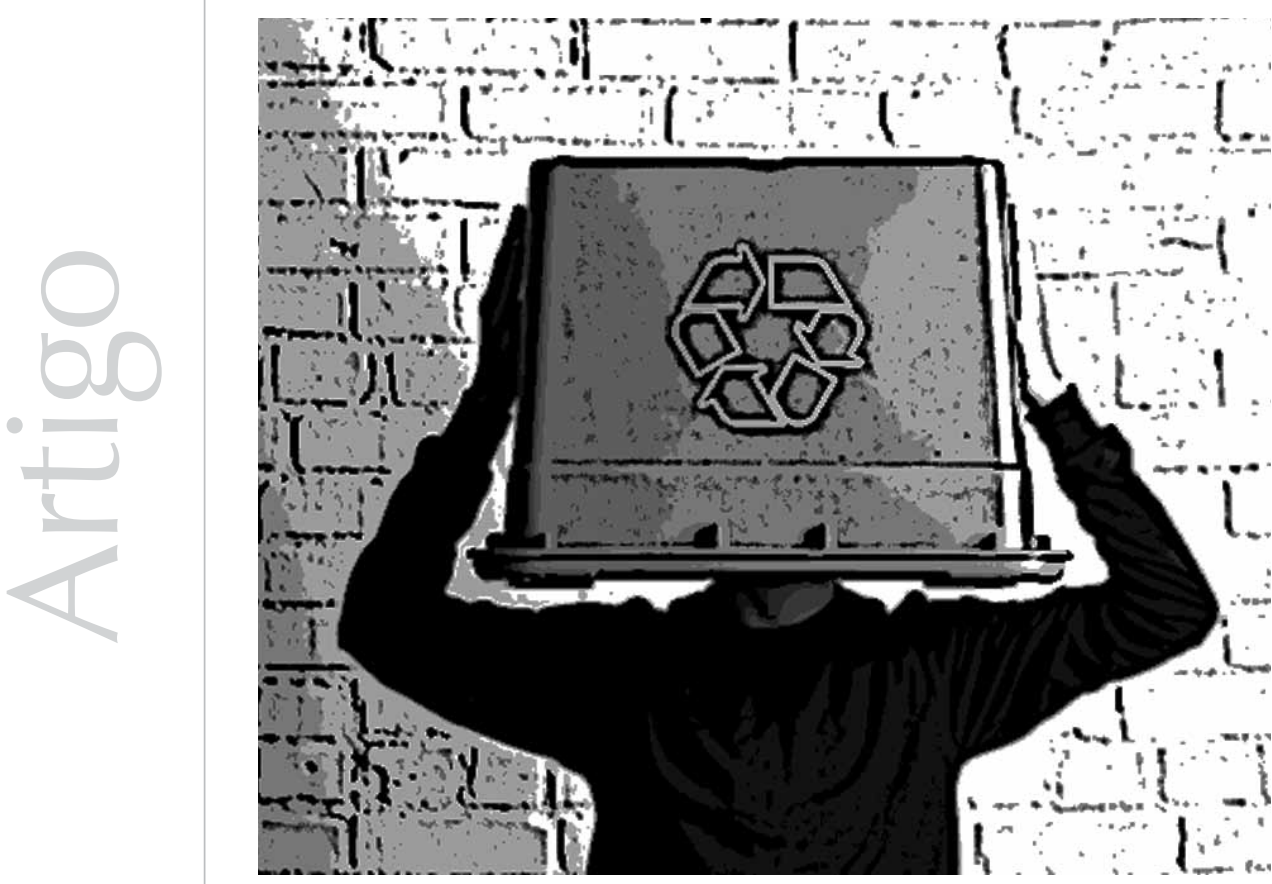
Resumo: Neste trabalho proponho a análise da ecologia nos processos de defesa ambiental através da Psicologia moral. É importante para essa área estender seu campo de análise a outras áreas fundamentais das necessidades e das relações humanas, e, nessa relação com a ecologia, as pesquisas são incipientes. A tese que se apresenta é de que a ecologia é moral. O grupo pesquisado foi de líderes ambientais do Estado de Rondônia, selecionados através do método de construção de redes. Utilizamos entrevista semiaberta, entrevista e dilemas morais ecológicos seguidos de entrevista-inquérito, na qual os participantes falaram de suas atividades na defesa ambiental e descreveram o histórico através do qual construíram uma consciência ecológica, e, ao responder aos dilemas morais, corroboram a tese, demonstrando a existência de uma personalidade moral ecológica, baseada na análise subjetiva da justiça e em princípios éticos universais. Os líderes apresentam também uma ética ecológica, uma ética verde baseada na sustentabilidade.

Palavras-chave: Juízo moral. Ecologia. Educação ambiental. Psicologia ambiental.

Abstract: The following paper proposes the analysis of ecology in the processes of environmental defense through the premises of moral psychology. It's important for this subject to broaden its analytical field to fundamental areas of human needs and human relations, and in relation to ecology, the research is incipient. The supported thesis argues that ecology is moral. The researched group was composed of environmental leaders of Rondônia, selected by network building. The semi-open interview and the moral ecological dilemmas followed by interview survey were used, and then the participants spoke about their activities concerning environmental defense and described the historical process through which an ecological conscience was formed, and while answering the questions on moral dilemmas, corroborated the thesis, showing the existence of a moral ecological personality, based on the subjective analysis of justice and on universal ethical principles. The leaders also present an ecological ethic, a "green" ethic based on sustainability.

Keywords: Moral judgment. Ecology. Environmental education. Environmental psychology.

Resumen: En este trabajo propongo el análisis de la ecología en los procesos de defensa ambiental a través de la Psicología moral. Es importante para esa área extender su campo de análisis a otras áreas fundamentales de las necesidades y de las relaciones humanas, y, en esa relación con la ecología, las pesquisas son incipientes. La tesis que se presenta es que la ecología es moral. El grupo pesquisado fue de líderes ambientales del Estado de Rondônia, seleccionados a través del método de construcción de redes. Utilizamos entrevista semi-abierta, entrevista y dilemas morales ecológicos seguidos de entrevistainvestigación, en la cual los participantes hablaron de sus actividades en la defensa ambiental y describieron el histórico a través del cual construyeron una consciencia ecológica, y, al responder a los dilemas morales, corroboran la tesis, demostrando la existencia de una personalidad moral ecológica, basada en el análisis subjetivo de la justicia y en principios éticos universales. Los líderes presentan también una ética ecológica, una ética verde basada en la sustentabilidad.

Palabras clave: Juicio moral. Ecología. Educación ambiental. Psicología ambiental.

Colocar ecologia e juízo moral lado a lado implica demonstrar que os estudos da Psicologia moral podem ser uma resposta para auxiliar no processo educativo de consideração e respeito ao meio ambiente natural e construído bem como no uso racional dos recursos naturais. Mas este é, antes de mais nada, um trabalho sobre Psicologia moral.

O que importa é que "precisamos desenvolver nossas próprias reflexões sobre como a Psicologia brasileira tem participado do tratamento dos graves problemas decorrentes da chamada crise ambiental, quer usando o rótulo de Psicologia ambiental ou não" (Pinheiro, 2001, p. 15).
A concepção de ecologia referenciada neste trabalho envolve sua dimensão natural, cultural e social. Percebemos a ecologia como a necessidade que temos de respeitar o meio ambiente natural na sua dinâmica de sobrevivência, sem deixar de considerar as relações humanas como causa e resultado da relação do ser humano com a natureza.

É assim que nos interessa aqui investigar se há moral autônoma nos participantes, se analisam a responsabilidade de forma subjetiva e se consideram as questões ecológicas a partir de princípios éticos universais. 


\section{Que ecologia é essa?}

É a história de um povo que construiu uma das sociedades mais adiantadas do mundo, pela tecnologia que chegaram a dominar. No entanto, esse desenvolvimento causou exigências imensas no meio ambiente que, quando não mais suportou essa pressão constante, fez com que a sociedade construída tão penosamente durante os milhares de anos antecedentes desaparecesse (Ponting, 1995, p. 21).

Essa descrição poderia ser relativa à nossa sociedade em um tempo futuro, mas o autor descreve a comunidade que vivia na Ilha de Páscoa muito antes da chegada dos colonizadores europeus. A história da humanidade está recheada desses exemplos, como as sociedades inca e maia. O que aprendemos desde então?

Muitas paisagens que conhecemos como naturais foram transformadas pela ação humana. "Na maior parte dos lugares onde o ser humano se estabeleceu, criou-se, a partir do ambiente selvagem, ambientes artificiais que se tornaram tão familiares a ponto de passarem por naturais, embora tenham origem cultural" (Dubos, 1981, p. 54), como, por exemplo, as ilhas desnudas do Mar Egeu e as costas rochosas da bacia do Mediterrâneo, que agradam inúmeras pessoas e que são o resultado de dois pecados capitais em ecologia: desflorestamento e erosão.

A forma de pensamento, os modos de produção e o modelo de progresso que vem sendo desenvolvido por nossa sociedade são prejudiciais à utilização racional dos recursos naturais. Essa metacrítica ao progresso é discutida no Brasil desde 1786, conforme os estudos de Pádua (2002). Se, desde o século XVIII, já temos os primeiros "momentos no processo de tomada de consciência dos dilemas ambientais" (Pádua, 2002, p. 29), quais as conquistas desde então?
No Brasil, no plano governamental, importantes atitudes têm sido tomadas para a implementação da educação ambiental. Dois elementos importantes são citados como grande avanço na questão ambiental, a saber: a Constituição Federal do Brasil (Brasil, 2000) e a participação na construção da Agenda 21 (Brasil, 1996).

Essa Agenda é o principal documento das Nações Unidas sobre meio ambiente e desenvolvimento humano, e foi gestada em solo brasileiro, no maior encontro mundial realizado até aquele momento sobre a questão ambiental, a Eco 92. As ações e as relações entre países desenvolvidos e em desenvolvimento passaram a ser balizadas por um conjunto de princípios: o princípio da precaução, o do poluidorpagador e o da responsabilidade comum, diferenciadamente entre países desenvolvidos e em desenvolvimento.

Em março de 1997, realizou-se, no Rio de Janeiro, a Rio +5 , onde foram avaliados os resultados práticos obtidos com os tratados assinados na Rio 92. Infelizmente, os participantes concluíram que havia se avançado muito pouco, e eram necessárias mais ações práticas. Os mesmos resultados foram encontrados pela Agenda 21 na Rio +10 , realizada em Joanesburgo, em 2002.

A legislação ambiental do Estado de Rondônia (Rondônia, 2000) também cumpre seu papel ao proporcionar ampla e atualizada visão ecológica, e desenvolveu um projeto de organização racional do espaço natural instituindo o Zoneamento SocioeconômicoEcológico do Estado (2005). Em 1997, o Ministério da Educação e Cultura lançou os Parâmetros Curriculares Nacionais - PCNs (Brasil, 1998), que inclui o meio ambiente como um dos temas transversais, e, em 1999, o Ministério do Meio Ambiente criou a Lei no 9.795, que institui a Política Nacional de Educação Ambiental. 
Como Dubos

(1981),

acreditamos em um namoro com a Terra.
É claro que essas questões são cruciais na formação da consciência ecológica, mas, de alguma forma, as atitudes ecológicas pontuais não têm sido suficientes, segundo os especialistas, para garantir a sobrevivência do ser humano nas próximas décadas. Esse aspecto é essencial, pois está presente na voz dos entrevistados. Há, para todos eles, a preocupação com o futuro, para que outros tenham os mesmos direitos e oportunidades de se relacionar com a natureza como estamos tendo. Isso é moral. Nossa crença é que o impasse pode ser resolvido através de abordagens educacionais ecológicas pautadas na Psicologia moral que discutam o papel dos indivíduos na relação consigo mesmos, com os outros, com o mundo.

Como Dubos (1981), acreditamos em um namoro com a Terra. E, como todo namoro, para ser gratificante e duradouro, é necessário que os parceiros se modifiquem e se adaptem ao processo de associação, mas "o efeito é bem mais interessante quando ambos os parceiros conservam elementos de sua individualidade, de seu próprio estado primitivo" (p. 66). E quais são as contribuições da Psicologia para esse processo? Podemos distinguir duas contribuições substanciais: a Psicologia ambiental e a ecopsicologia.

Partindo da ecofilosofia, Sylvan e Bennett (1994) discutem, de forma muito interessante, a construção de uma ética do ambiente, ética ecológica ou ética verde, que envolve a relação integral do ser humano com a natureza e a utilização racional dos recursos naturais. Os ecofilósofos concordam com a concepção de que o meio ambiente deve ser visto através de uma perspectiva ética, mas esclarecem que não há um consenso sobre o que seja uma ética ambiental. Incluímos, dessa forma, essa questão a ser pesquisada com os entrevistados, pois "uma ética ambiental envolve nova conceituação de comportamento adequado e inadequado com respeito ao meio ambiente" (p.09). É justamente isso que teremos a oportunidade de investigar, ao pesquisar, com os entrevistados, a Psicologia moral.

Para continuarmos a discussão, é necessário distinguir ética e moral. Se moral e ética são muitas vezes tomadas como sinônimos, é por desconhecermos sua fundamentação teórica. A moral engloba as diversas regras e valores dos homens, enquanto a ética é o estudo dessas regras e valores no campo filosófico, psicológico e sociológico. "A ética está para a moral como a epistemologia está para a ciência" (La Taille, 2001, p. 68). Enquanto na moral estão as leis, na ética estão os ideais que dão sentido à vida. Por isso Freitas (1999) concluiu que, para Piaget, somente quem tem uma personalidade autônoma é capaz de ação moral, pois esta implica uma relação com o outro, o que não é a única causa da ação moral, mas é desta uma implicação constante. Ação ética exige, para Freitas, possibilidade de raciocínio lógico, relação de respeito mútuo e constituição de uma tábua de valores. Não há sentimento de obrigação para com o outro senão no interior de relações interindividuais de respeito.

A Psicologia ambiental é uma nova área da Psicologia no Brasil que, segundo Günter e Rozestraten (1993), está presente nos Estados Unidos desde meados do século XIX. Para Melo (1991), a Psicologia ambiental tem início após a II Guerra, com a necessidade de reconstrução das cidades, surgindo como Psicologia da arquitetura "a partir da necessidade dos arquitetos de entenderem os requerimentos e as necessidades dos futuros ocupantes das grandes obras públicas" (p. 85), enquanto as recentes pesquisas, socialmente mais críticas sobre a inter-relação do ser humano com seu ambiente, considera "mais enfaticamente a ação das pessoas sobre os ambientes, assumindo mais integralmente a interdependência pessoa-ambiente" (Pinheiro, 1997, p. 387). 
Tassara (2001) defende, para a contemporaneidade, uma tarefa hercúlea que envolve uma verdadeira revolução de ideais científicos, pois implica enxergar o mundo, o ambiente, como algo produzido pelo homem em suas relações com a natureza e a ser construído pelas decisões de verdadeiras políticas ambientais a serem instaladas. (p. 6)

Já o termo Psicologia ecológica ou ecopsicologia é mais utilizado nos países de idioma germânico, enquanto, nos países da esfera anglo-americana, é mais utilizado o termo Psicologia ambiental, segundo o esclarecimento de Carneiro e Bindé (1997). Os ecopsicólogos "acreditam que haja um vínculo emocional entre os seres humanos e o meio ambiente natural pelo qual nos envolvemos" (Brown, 1995, p. xvi), e têm estado preocupados em resgatar a nossa ligação com a Terra, resgate de um self mais profundo - entendido aqui como a parte do self adaptado ao mundo natural, orgânico e inorgânico (Hilman, 1995).

Metzner (1999) é um psicólogo que prefere o termo green psychology ao de ecopsicologia. A razão do autor se assenta no fato de considerar que não temos condições de advogar a criação de uma nova subdivisão da Psicologia, que junta clínica, aspecto social e desenvolvimento, entre outras. Nesse sentido, não pretendemos discutir uma nova área para a Psicologia ambiental, mas sim, a ecologia como um aspecto da Psicologia moral ao procurarmos compreender como se deu o processo de construção e de desenvolvimento da personalidade moral, no aspecto ecológico, de pessoas ligadas à defesa ambiental.

\section{Psicologia moral e ecologia}

Consideramos a moralidade essencial para o bem que possamos fazer uns aos outros na construção de uma sociedade melhor e nas questões ecológicas, moral "cuja finalidade primeira é garantir a felicidade e o bemestar dos indivíduos" (La Taille, 1998, pp.
44-45). Também está inserida na concepção de moralidade deste trabalho a ideia de que a moralidade é referenciada pela cultura a que o sujeito pertence, e que não está restrita à obediência cega de parâmetros prédeterminados. Moralidade implica tomada de consciência e adesão, por livre arbítrio, a normas e regras.

O meio cultural dos indivíduos, contemporaneamente, diz respeito a conhecimentos cada vez mais divulgados sobre a ecologia, tornando-a, assim, um código moral do grupo a que se pertence, referenciado inclusive de forma legislativa e judiciária. A tomada de consciência é o que se espera de indivíduos que tenham a oportunidade de frequentar escolas e outros grupos (como associações, cooperativas, grupos de jovens) em que o tema vem sendo debatido, incluindo-se nesse aspecto a mídia das grandes massas, que frequentemente aborda o tema em todas as suas facetas.

Acreditamos que a questão ecológica seja também uma questão moral, pois envolve elementos self e other regarding - que se referem a si mesmo e ao outro. Assim sendo, uma pessoa ecologicamente moral é aquela que possui valores que regulam sua ação em função do respeito por si, por seu próprio espaço e sobrevivência mas também por outros, pelo valor à vida e pelo espaço que todos ocupam - o espaço público. São referenciais deste trabalho a Psicologia moral de Piaget (1994) e Kohlberg (1992), cujos princípios não nos deteremos a explicar aqui, já que podem ser facilmente pesquisados pelo leitor. Em vez disso, vamos nos debruçar na discussão do pensamento desses teóricos e de outros sobre a questão ecológica.

Sob o título de Promoção de Atitudes Ambientais Favoráveis Através dos Debates de Dilemas Ecológicos, Biaggio, Vargas, Monteiro, Souza e Tesche (1999), tal como propõe Kohlberg, tinham como objetivo proporcionar 
desenvolvimento moral a partir da discussão de dilemas com tema ecológico. O grupo era de alunos adolescentes, estudantes do ensino médio, e chegou a resultados qualitativos importantes, como a maturidade de atitudes e o favorecimento de atitudes ecológicas.

Eckensberger (2001), do Instituto Alemão para Pesquisa Internacional em Educação de Frankfurt/Main, Alemanha, em Juízos Morais no Contexto de Orientações de Valores Econômicos e Ecológicos, descreve um projeto de pesquisa, de grande escala, em juízo moral em um contexto de vida real acompanhar e analisar um conflito ecológico relacionado à construção de uma estação de força abastecida a carvão no distrito de Saarbrücke. Em uma comparação com a teoria kohlberiana, o autor concluiu que os indivíduos pesquisados, a favor ou contra a usina, analisaram a questão apenas no nível convencional.

\section{Personalidade moral}

Para Puig (1998), personalidade moral, ou moral self, significa construir representações de si mesmo em relação aos outros, ao mundo em que se insere, baseado em valores estabelecidos naquela cultura, onde se constrói o significado do eu e do não eu. Segundo o ponto de vista sistêmico de Blasi (1993), é preciso considerar onde se localiza a disposição para a moralidade em cada indivíduo, se central ou perifericamente. Essa proposição explica que comportamentos (morais) que são inquestionáveis para um determinado indivíduo podem não fazer parte dos conteúdos mais valorizados de outros. Enquanto honestidade, fidelidade, honra e ecologia podem estar no centro da personalidade de alguns indivíduos, na de outros, pode estar a necessidade de sentirse superior ao outro, de ter tudo para si, de consumir.
Foi isso o que Colby e Damon (1993) encontraram ao investigar pessoas de vida moral exemplar. Para essas pessoas, serem eles mesmos como identidade e como seres morais é a mesma coisa, pois os valores morais estão completamente integrados à sua personalidade.

\section{Moral e ecologia}

Para que a tese deste trabalho fique definitivamente esclarecida, é preciso compreender que existem ações morais e não morais. As ações necessitam de um conhecimento teórico e prático para serem realizadas, mas envolvem também a motivação de fazê-las. Para que uma ação seja moral, é necessário mais do que saber fazer corretamente aquela ação, é preciso que o motivo que leva o sujeito a executá-la seja moral.

Existem várias correntes na Psicologia moral que explicam as motivações morais. Historicamente e hoje, ainda com bastante força, estão as correntes piagetiana e kohlberiana, que se inspiraram em Kant. A moral kantiana dá a dimensão da obrigatoriedade, denominada imperativo categórico. É tal a condição cultural do sujeito envolvido pela sociedade, com suas normas e leis, que ele não pensa em fazer de outra forma.

Talvez alguns ecologistas não sejam morais, pois a inspiração que os leva àquela ação (defesa ambiental) não é ecológica, mas de poder, de ambição, de visualizar um meio de alcançar outra posição, status, fama, cargos, financiamentos. Mas a ecologia é moral. Certamente o imperativo categórico não é a única corrente da Psicologia moral para explicar as motivações morais. Atualmente se tem conhecimento da linha aristotélica, na qual a ética que inspira a moral é a felicidade, 
"em que toda ação e todo propósito visam a algum bem" (Aristóteles, 1996, I, 01, 118). A busca da felicidade é a busca da excelência moral.

Outra linha inspiradora da moral que se discute hoje é a ética do cuidado, de Carol Gilligan (1982), cujos estudos, relatados no livro Uma Voz Diferente, demonstram a voz do cuidado, pela qual considerar as consequências que envolvem moralmente todos os indivíduos em uma determinada situação é considerar mais que os direitos e deveres para cada um, é considerar o que se quer dar a cada um pela ética do cuidado.

Portanto, a partir do conhecimento de distintas proposições teóricas para a motivação moral, optamos por trabalhar com a abordagem kantiana. Assim, trabalhamos com a hipótese de que, embora haja afeto, preocupações e cuidados com o outro, a moral ecológica é uma moral do imperativo categórico, do dever de fazer, do não poder deixar de fazê-lo.

\section{Método}

O trabalho busca a compreensão de como se estruturou, nos líderes ambientais, a moral ecológica (que normas, que regras seguem?) e a ética (quais os valores e princípios em que acreditam?). Que identidade atribuem a si mesmos em relação à ecologia? - formação da personalidade moral. Há neles uma moral ecológica? Qual seria? Há neles uma ética ecológica? Qual seria? Aproxima-se da moral kantiana?

Os líderes ambientais que estão em ação têm uma moral ecológica? Nossa tese é de que a resposta é afirmativa. E mais, a compreensão moral dos líderes ecologistas é traçada pela subjetividade e é determinada por princípios éticos universais, tendo como importante raciocínio os elementos afetivos. Ecologia, ainda, é other regarding, ou seja, é baseada no respeito e na consideração pelo outro, mais do que por si mesmo.

\section{Entrevistados 1}

O objetivo da pesquisa encaminhou a escolha dos participantes a pessoas que conhecessem o assunto na teoria e na prática e que militassem na área da ecologia. Desde o princípio, tivemos como foco de interesse compreender como líderes na defesa ambiental haviam construído uma consciência moral ecológica.

Os critérios para seleção dos componentes desse grupo advêm da contribuição teórica de Bom Meihy (1996), que define como colônia, padrões gerais de uma determinada comunidade, traços preponderantes que ligam a trajetória das pessoas e definem a formação de uma rede, nesse caso, dentro da militância na defesa ambiental "que visa a estabelecer parâmetros para decidir quem deve ser entrevistado ou não" (p.53). A definição do grupo atendeu, pois, ao requisito de serem pessoas de reconhecida consciência ecológica e respeitada atuação no campo da defesa ambiental. Salientamos que a ação desses líderes não se limita à cidade onde residem, pois todos têm atuação que atinge não só a cidade de Porto Velho mas também o interior do Estado. Foram ao todo nove entrevistados: seis de Porto Velho e três do interior do Estado de Rondônia (Ouro Preto D'Oeste, Ji-Paraná e Cacoal).

\section{Procedimento}

No procedimento metodológico combinamos entrevista semidirigida, entrevista- inquérito e o dilema moral. A entrevista semidirigida foi intercalada aos demais instrumentos, e serviu para traçar um panorama das ações ecológicas do entrevistado, investigar questões relativas 
à motivação ecológica, à consciência moral e à ética ecológica, bem como se mostrou importante para demonstrar como ocorreu, em cada indivíduo, o desenvolvimento simultâneo da formação da consciência moral autônoma e do desenvolvimento de suas capacidades ou procedimentos de reflexão e ação, como o sujeito se representa e se essas representações são valorativas.

Na entrevista semidirigida, usamos o seguinte roteiro: (a) identificar a presença de subsídios para afirmar a ecologia como tema moral; (b) verificar se a moral ecológica é central/ periférica na personalidade dos indivíduos; (c) verificar se a moral ecológica, como a própria defesa ambiental, é self ou other regarding (orientada para si mesmo ou para os outros), e (d) compreender a construção da personalidade moral dos entrevistados no contexto da ecologia.

A técnica da entrevista-inquérito foi desenvolvida por La Taille (2003), e o autor assim a descreve:

Fornecemos ao sujeito um fato bruto... e deve ele formular perguntas (às quais respondemos apenas "sim" ou "não" - ou ainda "não sei", se a pergunta não for relevante)... sobre esse fato para julgar a legitimidade moral do ocorrido. Para tal, é claro que devemos ter inventado uma história previamente, para poder responder às perguntas. (p. 20)

Com essa orientação, conduzimos a apresentação da técnica com a seguinte fala: Vou lhe apresentar um fato em apenas uma frase. Você deverá julgar se o comportamento do personagem em questão está correto ou incorreto, justificando sua posição. Para chegar ao julgamento final, você poderá fazer perguntas acerca das circunstâncias que envolvem a informação. Portanto, o objetivo aqui é que você me diga se o personagem está agindo corretamente ou não e por quê. As duas frases brutas utilizadas na entrevistainquérito estão citadas abaixo, seguidas das histórias que criamos, mas que não foram reveladas aos entrevistados.
1. Sebastião come carne de paca.

Sebastião, um sujeito natural da região, cresceu dentro dos seringais, tem família de cinco filhos e ganha seu sustento a partir da caça, da coleta, de um pouco de produção de borracha e de pequenos bicos nas vizinhanças. A caça representa valioso complemento protéico na alimentação da família.

2. Grupo de ecologistas explode barco pesqueiro

Trata-se de grande barco pesqueiro no litoral sudeste do Brasil, em alto mar, que trabalha com pesca de médio porte para consumo comercial. Sua bandeira é estrangeira. Não costumam respeitar o período da proibição. Como são interpretados os dados da entrevistainquérito? Novamente La Taille (2003) nos orienta: pelo conteúdo das perguntas e pelo próprio juízo de legitimidade.

Nossa hipótese foi que os entrevistados regulam a moralidade pela subjetividade, e legitimam os atos ecológicos que dependam de questões sociais justas e necessárias. Para tanto, esperávamos que o conteúdo das questões feitas se dirigisse a aspectos particulares da situação, como: onde mora, quais os dados familiares, do que se sustenta, que tipo de barco, e tendessem a legitimar a caça da carne de paca e a condenar a explosão do barco.

O dilema moral, como instrumento de avaliação, constitui um método indireto de verificação a respeito de como determinada pessoa avalia essa ou aquela conduta. $\mathrm{O}$ suporte teórico para essa escolha metodológica está em Piaget.

O dilema apresentado aos entrevistados foi o seguinte: Pedro é um fazendeiro que, no mês passado, precisou retirar $10 \mathrm{~m}^{3}$ de madeira para fazer uma casa. Para autorizar 
o desmatamento, o IBAMA cobra uma taxa de R \$X. Pedro achou abusiva. Não pagou a taxa, retirou as madeiras clandestinamente e plantou três alqueires com várias plantas da região, como ipê roxo, castanheira e jacarandá. Seguido do inquérito com as questões: (a) Você acha que Pedro agiu certo? Por quê (justificativa)? (b) Você acha correto desobedecer a uma lei mesmo compensando-a clandestinamente?

"Os dilemas morais são construídos a partir de hipóteses psicológicas a respeito do nível de desenvolvimento do sujeito e das variáveis culturais" (La Taille, 2003, p. 21). A hipótese estabelecida para a elaboração desse dilema foi que o importante é a consciência de utilizar racionalmente a floresta. Se Pedro discorda da forma de ação dos órgãos públicos, isso não afeta seu senso moral ecológico de responsabilidade com o ambiente e de respeito à natureza como produtora dos recursos que ele utiliza. O aspecto fundamental na aplicação do dilema é a entrevista clínica que se seguiu ao dilema, na qual esclarecemos as razões de cada posição.

Nossa hipótese era que os entrevistados seriam capazes de perceber uma moral autônoma, baseada na responsabilidade subjetiva. Os ecologistas tenderiam a aceitar a substituição que Pedro fez, tendo em vista ser a moral ecológica um valor central de suas personalidades.

\section{Resultados}

\section{Dados advindos das entrevistas semidirigidas}

Identidade que atribui a si mesmo em relação à ecologia

Percebemos que a construção da identidade dos entrevistados em relação à ecologia se deu através de situações emocionalmente vivenciadas em oito dos nove entrevistados, com mais ênfase para alguns. Alegria e dor na percepção das mudanças ambientais foram colaboradores essenciais para essa construção:

Então, sempre que eu posso falar, eu falo com todas as pessoas sobre isso, eu mostro algumas fitas e eles acham bonito e eu falo, olha o Rio Branco, o rio tal era assim, sabem quem acabou? Fui eu, foi você.

Familiares muito próximos, como pai, mãe, avó e tio foram importantes colaboradores nesse processo, sendo os pais citados como pólo da tomada de consciência ambiental em quatro das nove entrevistas. Em todos houve um processo contínuo e crescente de tomada de consciência conduzido pela situação vivida pelos sujeitos. A cultura que os cercava foi decisiva. A vivência em ambientes naturais foi marcante, na zona rural, ou esporadicamente, em período de férias: “ $O$ rio Capibaribe... ficava bem próximo da casa da minha tia, eu ia pra lá e era só mato".

\section{Motivação ecológica e consciência moral autônoma}

Para todos os entrevistados, a motivação para trabalhar com a defesa ambiental envolve uma consciência moral autônoma, com razões construídas a partir das experiências pessoais e da cultura em que se inserem. Para tanto, refletem sobre as razões que os levaram a tal posicionamento.

A motivação dos entrevistados para trabalhar na defesa ambiental está calcada em elementos refletidos e analisados à luz de suas experiências. As declarações revelam pessoas que trabalharam com fatos e situações que Ihes aconteceram e que calcaram suas regras a partir dos resultados das situações e dos relacionamentos: “a minha (motivação) é de que as pessoas enxerguem o que eu enxerguei. De destruidor a preservador. De que realmente faz diferença a pessoa ajudar 
ou não na conservação". "É o compromisso de estar ali... Sonho em ver nas comunidades que a gente trabalha o pessoal falando melhor, se colocando melhor, se organizando mais". "Na medida que a gente incorpora isso, se transforma numa filosofia de vida, então... eu não me furto, eu faço... sua imagem parece que começa refletir aquilo que você faz, então dificilmente você desassocia".

\section{Motivação ecológica e imperativo categórico}

Podemos dizer que o motivo dos entrevistados para trabalhar com a defesa ambiental é moral, porque envolve um querer moral, ou seja, o dever de fazer algo. Remete ao imperativo categórico, porque é algo que os entrevistados sentem não poder deixar de fazer. Encontramos essa categoria na fala de oito dos nove entrevistados: "Eu me sinto assim no dever de tentar fazer alguma coisa, de tentar educar, de tentar mostrar um outro futuro pras crianças... Me sinto no dever de estar fazendo alguma coisa pra ajudar".

\section{Motivação ecológica e amor pela natureza}

Para dois entrevistados, a motivação para trabalhar na defesa ambiental está ligada ao amor pela natureza, ao amor pelo lugar em que mora, principalmente a partir da identidade que criou a Amazônia e suas características peculiares. Ressalto que esses mesmos entrevistados também registram uma moral ecológica autônoma nas razões para a defesa ambiental e que, em suas entrevistas, comparecem preocupações morais e sociais fundamentais: "gostar da natureza. Eu amo muito, muito, muito esse Estado, amo muito a Amazônia, não quero sair daqui, considero aqui a minha casa. ...é o lugar que amo, que escolhi viver". "Eu adoro um rio, adoro uns bichinhos livres, adoro ter a certeza que minhas duas filhas vão poder nadar tranquilas dentro do rio. Eu sou apaixonada por cachoeira, pelo prédio do relógio, pela Estrada de Ferro Madeira Mamoré".

\section{Moral ecológica e orientação other regarding}

É muito clara, na fala de todos os entrevistados, a disposição other regarding, orientada para o bem-estar do outro, da moral ecológica. Isso é um elemento importante para a comunidade mundial. Na ecologia e na defesa ambiental, está a preocupação com os outros, com a sobrevivência das comunidades, com a preservação das condições de qualidade de vida do Planeta: "a gente quer deixar algumas coisas para quem vai ficar depois da gente, para outras pessoas".

\section{Ética verde: o princípio da sustentabilidade}

Sylvan e Bennett (1994) comentam que hoje se discute se haveria uma ética verde. Se existe, qual seria? Uma contribuição a isso, possibilitada pelas respostas dos entrevistados, é o fato de que há uma ética verde, e essa ética defende o princípio da sustentabilidade. Moralmente, trata-se de defender a preservação da natureza como meio de sobrevivência da humanidade. A natureza não é um fim em si mesma, é um meio para a preservação do ser humano.

Na fala de todos os entrevistados, é nítida a ideia de que a natureza é maravilhosa, mas o ser humano é mais importante. Pol (2001), descrevendo o histórico da Psicologia ambiental na Europa, já apontava essa tendência a partir de meados da década de 80 e início da década de 90. "Fazer com que a degradação, a exploração, seja o mais sustentável possível. Não sei nem se a gente pode usar o termo sustentável, mas que o uso pelas comunidades seja o mais sustentável". "Englobar as necessidades do indivíduo e 
a preservação, porque não podemos fazer um retrocesso na natureza, acho que hoje nós estamos caminhando numa situação de domesticação das coisas, pra você usar com mais frequência.... Ou nós fazemos isso ou eles desaparecerão".

\section{Dados advindos das entrevistas-inquérito}

\section{Julgamento de Sebastião, que come carne de paca.}

Nossa hipótese nesse instrumento se confirmou. O conteúdo das questões foi direcionado para aspectos particulares da situação: Ele mora onde? Ele faz isso todos os dias? A condição financeira dele é pobre? Ele é casado? Tem filhos? É proprietário de terra? Tem uma renda que poderia fazer com que evitasse comer carne de caça? Todos os entrevistados legitimaram a atitude de Sebastião, mas sempre colocando a condição de que isso deve ser para o seu sustento e o de sua família, que a carne não pode ser vendida, pois esse ato mudaria a legitimidade da situação.

\section{Julgamento do grupo de ecologistas que explode barco pesqueiro}

Novamente a hipótese se confirmou, nesse caso, de forma ainda mais contundente. Apenas um entrevistado legitimou o ato de explodir um barco pesqueiro, mas apenas se este estivesse pescando em período proibido. Oito dos nove entrevistados são expressamente contrários a esse tipo de atitude na defesa ecológica. Argumentam pela negociação, pela conversação, e não a se assemelhar às formas de os tradicionais agressores agirem.

Tal fato vem corroborar os resultados obtidos na entrevista semidirigida, na qual os entrevistados apresentam uma moral ecológica baseada na racionalidade e na sustentabilidade. Costumam apontar inovadoras formas de lidar com a problemática e são capazes de fazer desde macroanálises da situação global de agressão ao meio ambiente até questões particulares, subjetivas, nas quais a necessidade e o contexto do sujeito envolvido são considerados relevantes, como é o caso de nosso fictício, porém não hipotético, Sebastião.

Novamente aspectos do imperativo categórico. Aquilo que está na cultura do indivíduo é que torna a situação um imperativo do dever. A premência de atender a necessidade de sobrevivência do ser humano torna um dever defender esse ser humano. Isso é um imperativo categórico:

\begin{abstract}
Eu acho errado, acho errado. Eu não concordo de explodir o barco. Concordo sim que, por exemplo, que eles respeitem as leis, concordo que nós devamos fiscalizar nosso litoral, concordo que o Brasil deva exercer pressão pra que esse pessoal não venha pescar aqui, concordo que outras medidas devem ser tomadas. Não, não concordo não.... senão a gente vai estar agindo igualzinho o cara que invade a terra indígena, igualzinho o cara que rouba madeira da unidade de conservação.
\end{abstract}

\section{Dados advindos da apresentação do dilema moral}

\section{Julgamento da ação de Pedro}

Nesse aspecto, há uma diferença de opinião dentro do grupo de entrevistados. Cinco entrevistados acham que Pedro agiu corretamente, concordam que a substituição feita por Pedro é ecologicamente aceitável, mas quatro entrevistados consideram a atitude de Pedro incorreta, e defendem o cumprimento da lei.

Pode-se dizer que os entrevistados tendem à hipótese estabelecida para a elaboração desse 
dilema, que o importante é a consciência de utilizar racionalmente a floresta, assim como tendem a aceitar a substituição que Pedro fez. Mas, ao contrário das outras hipóteses, em que estava clara a unanimidade de opinião entre os entrevistados, precisamos voltar aqui às justificativas para compreender que, embora defendam a lei, não desconsideram a atitude de Pedro como ecologicamente aceitável. A importância em cumprir as leis estabelecidas advém da necessidade de se firmar contratos e de respeitá-los.

A questão (b) foi elaborada exatamente para dirimir essas dúvidas. Todos os entrevistados concordaram com o fato de que a lei é uma expressão genérica e que precisa ser examinada à luz de cada caso: "a lei existe para a generalidade, e não pra especificidade". Isso confirma mais uma das hipóteses deste trabalho. A moral ecológica dos entrevistados é regulada pela subjetividade. Há, na justiça aceita e executada por eles, uma noção de responsabilidade subjetiva.

\section{Considerações finais}

A voz dos líderes ambientais pesquisados é uma voz ecologicamente moral. A ecologia é um tema moral, e, como tal, baseada em princípios teóricos e práticos da Psicologia moral, e deve também ser abordada nos processos educativos de defesa ambiental. Essas são possibilidade e alternativa necessárias para que os programas de sensibilização, na defesa de maior qualidade de vida para os seres humanos, se realizem.

A ecologia é moral em todas as suas dimensões. Isso significa dizer que não o é apenas no juízo moral mas também na ação moral. Na definição cognitiva/intelectual, está o saber fazer, e, na afetiva, o desejo de fazer, de querer fazer de acordo com o princípio defendido. Assim é para os entrevistados. Não há só uma compreensão de como deve ser feito, mas a motivação para fazê-lo segue os princípios de uma ética verde de sustentabilidade na utilização racional dos recursos naturais. E assim o é pela construção de uma consciência moral autônoma ligada às questões da ecologia.

Para tanto, representam-se através de elementos ligados à natureza e à necessidade de trabalhar em projetos que auxiliem outros seres humanos, não a si próprios, pois demonstram uma moral ecológica other regarding. Consideram que estão vivendo em uma Terra que oferece fartura e abundância de recursos, matas, rios, oxigênio de qualidade, e querem garantir esse direito a outras pessoas. É a defesa de um princípio ético universal dos direitos humanos.

Representam-se valorativamente na descrição de suas vidas, relatando como foram adquirindo conhecimentos, vivências, ao longo de seu contato com a natureza, identificando-se com valores positivos e defendendo princípios éticos universais de igualdade e justiça para todos. A ecologia é um valor central na personalidade dos entrevistados, que construíram sua identidade sobre a defesa ambiental e que se caracterizam e se valorizam a partir dessa relação.

Há uma ética ecológica que circunscreve a defesa ambiental dos entrevistados; a ética verde dos entrevistados é a ética da sustentabilidade. Certamente, alguns têm uma relação mais próxima com a natureza e trabalham em projetos de preservação, mas nenhum deles se mostrou inclinado a defender a ideia de preservação da natureza pela natureza.

Não foi objetivo traçado para este trabalho avaliar a competência ecológica, mas, se a proposta é expandir os conhecimentos aqui obtidos para programas de educação ambiental, não há porque não comentar 
que os entrevistados demonstram, com grande ênfase, o que Corral-Verdugo, VarelaRomero e González-Lomeli (2004) chamam de competência pró-ambiental (CPA), que pode ser definida como "uma capacidade de responder efetivamente às exigências de conservação do meio ambiente, ações pró-ambientais como comportamentos de conservação efetivos" (pp. 41-42).

São exatamente comportamentos efetivos de conservação que se vê na vida pessoal e profissional dos entrevistados. Não só conhecem os problemas ambientais de perto mas também sabem resolvê-los de forma motivadora, apresentando soluções possíveis e cabíveis. A partir das informações obtidas através da construção das identidades dos entrevistados na relação com a ecologia, é possível assinalar que, para a efetividade dos programas de educação ambiental, é necessário proporcionar uma convivência mais próxima, mais emocional, com a natureza.

Como psicólogos, sabemos que, se a informação é necessária, não é suficiente. Pressupõe que o ser humano seja sobretudo racional e coerente. Isso significa não considerar complexos processos afetivos e de influência social, entre outros tantos que mascaram a possibilidade da racionalidade. (Pol, 2001, pp. 64-65)

A ação ecológica nem sempre é moral, pois, por trás de uma atitude de defesa ambiental, pode não haver uma ética verde, pode não haver um desejo moral ecológico. Mas isso não foi o que encontramos nos líderes ambientais entrevistados, pois eles possuem uma personalidade moral ecológica e, segundo o que entendemos, a orientação dessa moral ecológica é kantiana, já que existe um imperativo categórico na compreensão moral ecológica dos líderes entrevistados.

Vanessa Aparecida Alves de Lima

Doutora em Psicologia escolar e do Desenvolvimento Humano, Universidade de São Paulo, São Paulo - SP - Brasil. E-mail: limavanessa@uol.com.br

Endereço para envio de correspondência:

Rua dos Sonhos, 2711. Residencial Forte Príncipe, Bairro dos Tanques. Porto Velho, RO - Brasil - CEP 76 803-510.

Recebido 22/12/2008, 1a Reformulação 21/11/2009, 2a Reformulação 05/03/2010 , Aprovado 30/03/2010. 


\section{Referências}

Aristóteles. (1996). Ética a Nicômaco. São Paulo: Círculo do Livro.

Biaggio, A. M. B., Vargas, G. A. de O., Monteiro, J. K., Souza, L. K., \& Tesche, S. L. (1999). Promoção de atitudes ambientais favoráveis através dos debates de dilemas ecológicos. Estudos de Psicologia, 4(2), 221-238.

Blasi, A. (1993). The development of identity: Some implications for moral functioning. In G. G. Noam \& E. Wren (Eds.), The moral self (pp. 99-122). Cambridge: The Mit Press.

Bom Meihy, J. C. S. (1996). História oral. São Paulo: Loyola.

Brasil (1996). Agenda 21: Conferência das Nações Unidas sobre Meio Ambiente e Desenvolvimento. Rio de Janeiro: Senado Federal: Subsecretaria de Edições Técnicas.

Brasil. Secretaria de Educação Fundamental. (1998). Parâmetros curriculares nacionais: terceiro e quarto ciclos: apresentação dos temas transversais. Brasília, DF: MEC.

Brasil. (2000). Constituição da República Federativa do Brasil (24a ed.). São Paulo: Saraiva.

Brown, L. R. (1995). Ecopsychology and the environmental revolution: An environmental foreword. In T. Roszak, M. E. Gomes \& A. D. Kanner, Ecopsychology (pp. xiii-xvi). United States of America: Sierra Books.

Carneiro, C., \& Bindé, P. J. (1997). A psicologia ecológica e o estudo dos acontecimentos da vida diária. Estudos de Psicologia, 2(2), 363-376.

Colby, A., \& Damon, W. (1993). The uniting of self and morality in the development of extraordinary moral commitment. In G. G. Noam \& E. Wren (Eds.), The moral self (pp. 148-174). Cambridge: The Mit Press.

Corral-Verdugo, V., Varela-Romero, C., \& González-Lomeli, D. (2004). O papel da psicologia ambiental na promoção de competência pró-ambiental. In E. T. O. Tassara, E. P. Rabinovich \& M. C. Guedes (Eds.), Psicologia e ambiente (pp. 41-57). São Paulo: EDUC.

Dubos, R. (1981). Namorando a terra. São Paulo: Melhoramentos.

Eckensberger, L. H. (2001). Juízos morais no contexto de orientações de valores econômicos e ecológicos: o caso de uma usina de força abastecida a carvão. In E. Tassara (Ed.), Panoramas interdisciplinares para uma psicologia ambiental do urbano (pp. 141-186). São Paulo: EDUC.

Freitas, L. B. L. (1999). Do mundo amoral à possibilidade de ação moral. Psicologia: Reflexão e Crítica, 12(2), 447-458.

Gilligan, C. (1982). Uma voz diferente. Rio de Janeiro: Rosa dos Tempos.

Günter, H., \& Rozestraten, R. J. A. (1993). Psicologia ambiental: algumas considerações sobre sua área de pesquisa e ensino. Psicologia: Teoria e Pesquisa, 9(1), 107-122.

Hilman, J. (1995). A psyche the size of the earth: A psychological foreword. In T. Roszak, M. E. Gomes \& A. D. Kanner, Ecopsychology (pp. xvii-xxiii). United States of America: Sierra Books.

Kant, E. (1936). Fundamento da metaphysica dos costumes. São Paulo: Edições e Publicações Brasil.

Kohlberg, L. (1992). Psicologia del desarrollo mental. Bilbao: De Desclée.

La Taille, Y. (1998). Limites: três dimensões educacionais. São Paulo: Ática.
La Taille, Y. (2001). A questão da indisciplina: ética, virtudes e educação. In P. Demo, J. Hoffman \& Y. La Taille, Grandes pensadores da educação (2a ed., pp. 67-98). Porto Alegre: Mediação.

La Taille, Y. (2003). Moralidade e violência: a questão da legitimação de atos violentos (projeto de pesquisa). São Paulo: FAPESP.

Melo, R. G. C. (1991). Psicologia ambiental, uma nova abordagem da psicologia. Psicologia USP, 2(1/2), 85-103.

Mendonça, C. D. (2000). Pesquisa ação sobre procedimentos de educação ambiental. Monografia de graduação, Curso de Biologia, Universidade Federal de Rondônia, Porto Velho, RO.

Metzner, R. (1999). Green psychology. Rochester, Vermont: Park Street Press.

Pádua, J. A. (2002). Um sopro de destruição: pensamento político e crítica ambiental no Brasil escravista (1786-1888). Rio de Janeiro: Jorge Zahar.

Piaget, J. (1994). O juízo moral na criança. São Paulo: Summus.

Pinheiro, J. Q. (1997). Psicologia ambiental: a busca de um ambiente melhor. Estudos de Psicologia, 2(2), 277-398.

Pinheiro, J. Q. (2001). (Um pouco da) Psicologia ambiental no Brasil: identidade, incertezas, perspectivas. In E. Tassara (Ed.), Panoramas interdisciplinares para uma psicologia ambiental do urbano (pp. 11-26). São Paulo: EDUC.

Pol, E. (2001). Ejes de tensión y nueva agenda para la psicologia ambiental. Una perspectiva europea. In E. Tassara (Ed.), Panoramas interdisciplinares para uma psicologia ambiental do urbano (pp. 51-67). São Paulo: EDUC.

Ponting, C. (1995). Uma história verde do mundo. Rio de Janeiro: Civilização Brasileira.

Puig, J. M. (1998). A construção da personalidade moral. São Paulo: Ática.

Rondônia. (1986). Zoneamento socioeconômico-ecológico do Estado de Rondônia. Revista Zoneamento Socioeconômico. Recuperado em 12 de abril de 2008, de http://www.rondonia. ro.gov.br/revistas/zoneamento

Rondônia. (2000). Legislação Ambiental do Estado de Rondônia: Lei Complementar $n^{\circ} 233$ de 6 de junho de 2000. Regulamenta a legislação das ações ambientais, de degradação à compensação e preservação do Estado de Rondônia. Porto Velho, RO: Insight Comunicação.

Sylvan, R., \& Bennett, D. (1994). The greening of ethics. Cambridge: The White Horse Press and Tucson.

Tassara, E. T. O., Rabinovich, E. P., \& Guedes, M. C. (Eds.). (2001). Psicologia e ambiente. São Paulo: EDUC. 